\title{
UV Raman Spectroscopic Characterization of Catalysts and Catalytic Active Sites
}

\author{
Shaoqing Jin $\cdot$ Zhaochi Feng $\cdot$ Fengtao Fan • \\ Can Li
}

Received: 1 October 2014/ Accepted: 28 October 2014/Published online: 11 November 2014

(C) Springer Science+Business Media New York 2014

\begin{abstract}
UV Raman spectroscopy has been demonstrated to be a powerful technique in catalysis because it can avoid the fluorescence interference occurring in visible Raman spectroscopy and concurrently enhance the Raman scattering intensity owing to the short wavelength of the excitation laser and resonance Raman effect. This article briefly reviews the recent advances in the study on heterogeneous catalysis by UV Raman spectroscopy, including the identification of isolated transition metal ions in molecular sieves, in situ study of zeolite assembly mechanisms and catalytic reaction mechanisms, and the monitoring of the surface phase transformation of metal oxide photocatalysts. UV (resonance) Raman spectroscopy, with the power of resonance enhancement for Raman signal and the advantage of high sensitivity for surface structure, coupling with in situ methodology, can provide the information about the active sites/phase and their assembling mechanisms, which are helpful for the understanding of heterogeneous catalysis and the rational design of highly active and selective catalysts.
\end{abstract}

Keywords UV Raman · Catalysis · In situ · Mechanism · Surface phase junction

S. Jin $\cdot$ Z. Feng $\cdot$ F. Fan $(\bowtie) \cdot$ C. Li $(\bowtie)$

State Key Laboratory of Catalysis, Dalian Institute of Chemical Physics, Chinese Academy of Sciences, Dalian 116023, China e-mail: ftfan@dicp.ac.cn

C. $\mathrm{Li}$

e-mail: canli@dicp.ac.cn

S. Jin

University of the Chinese Academy of Sciences, Beijing 100049, China

\section{Introduction}

Heterogeneous catalysis has been playing a great role in chemical processes [1-3]. However, the characterization of catalytic active sites and the understanding of catalytic active sites remain challenging $[4,5]$. Over the past decades, numerous techniques have been developed and used for the study of heterogeneous catalysis [6-13]. For example, Weckhuysen et al. [14] have monitored in situ phase changes in a complex iron-based Fisher-Tropsch catalyst and the nature and location of produced carbon species by scanning transmission X-ray microscopy, opening new opportunities for nanometer-resolution imaging of a range of important chemical processes occurring on solids in gaseous or liquid environments; Baiker et al. $[15,16]$ have systematically examined the catalytic solid/liquid interfaces using attenuated total reflection Fourier transform infrared spectroscopy, the kinetics of complex reactions can be followed by quantifying the concentration of reactants and products simultaneously in a non-destructive way with the in situ technique. With the development of experimental devices for in situ solid state NMR measurements, NMR spectroscopy has been widely used for the study of the adsorption of reactants on active sites, the identification of reaction intermediates and products, and the elucidation of reaction mechanisms of heterogeneous catalysts nowadays [17, 18].

Among the characterization techniques, Raman spectroscopy is considered to be a powerful tool for the study of heterogeneous catalysis. It can provide the chemical structure information about both the solid catalyst and the surface species in a single measurement $[19,20]$. The wide spectral range $\left(50-4,000 \mathrm{~cm}^{-1}\right)$ and high spectral resolution $\left(\sim 1 \mathrm{~cm}^{-1}\right)$ enable Raman spectroscopy to identify the crystalline phase of solid, determine the structure of surface 
amorphous phase and examine the nature of molecular species. In spite of this, conventional Raman spectroscopy with visible laser as the excitation source often fails to work in solid catalyst characterization due to the strong fluorescence interference caused by impurities, organic species and defect sites [21-23].

One efficient way to avoid fluorescence interference could be time-gating methods [24], including either pulsegating or optical Kerr-gating. Because the lifetime for Raman process $\left(10^{-11}-10^{-13} \mathrm{~s}\right)$ is much shorter than that for fluorescence process (usually $10^{-6}-10^{-9} \mathrm{~s}$ ), Raman and fluorescence signals can be well separated by the timegating methods using a picosecond pulsed excitation laser and a synchronized, gated detector (and Kerr-medium for Kerr-gating). However, the drawbacks of these methods are also prominent: the potential for sample destruction caused by the very short pulse laser with high peak power; the limitation to excitation lines in the visible to near IR region [24].

As the fluorescence is produced mainly from the transition from the first excited electronic state to the vibrational states of ground electronic state, fluorescence band primarily appears in the range from 300 to $700 \mathrm{~nm}$ or the longer wavelength region, and it doesn't change with the variation of excitation wavelength. However, Raman signal shifts as the excitation line shifts. Therefore, the fluorescence interference could be avoided by shifting the excitation wavelength from the visible region to the IR or UV region [25] as shown in Fig. 1a. In the 1980s, the development of FT Raman spectroscopy and UV Raman spectroscopy has dramatically increased the utility and applicability of Raman spectroscopy [26-29]. FT Raman spectroscopy using near IR laser as the excitation line has the advantage to increase the spectral $\mathrm{S} / \mathrm{N}$ with a Michelson interferometer as the light dispersion system. However, FT Raman measurements are problematic with samples at elevated temperatures because of the background arising from sample luminescence [23] and the Raman intensity is relatively low due to the scattering law inversely proportional to the fourth power of excitation wavelength. The shortcomings limit its application in heterogeneous catalysis.

The situation is different for UV Raman spectroscopy, besides the avoidance of fluorescence interference, the sensitivity is remarkably improved owing to the short wavelength of the excitation laser. Figure $1 \mathrm{~b}$ shows the Raman spectra of $\mathrm{AlPO}_{4}-5$ excited at 532, 325, and $244 \mathrm{~nm}$. The spectrum excited at $532 \mathrm{~nm}$ is dominated by fluorescence. When the excitation line shifts to $325 \mathrm{~nm}$, Raman signal with a weak fluorescence background can be collected. Further more, Raman spectrum of $\mathrm{AlPO}_{4}-5$ with no fluorescence background and high quality can be obtained with $244 \mathrm{~nm}$ excitation. The example clearly reflects the advantages of UV Raman spectroscopy, no fluorescence interference and high sensitivity. Since the electronic transition of chemical compounds are usually located in the UV region, the other advantage of UV Raman spectroscopy is that resonance Raman spectroscopic study can be carried
Fig. 1 a UV Raman spectroscopy avoiding fluorescence interference while increasing Raman scattering intensity; b Raman spectra of $\mathrm{AlPO}_{4}-5$ excited at 532, 325, and $244 \mathrm{~nm}$; c A schematic description of UV resonance Raman spectroscopy, the Raman bands attributed to $S$ and $\mathrm{T}$ components can be selectively enhanced by shifting the excitation laser lines towards their UV-visible absorption bands (a)

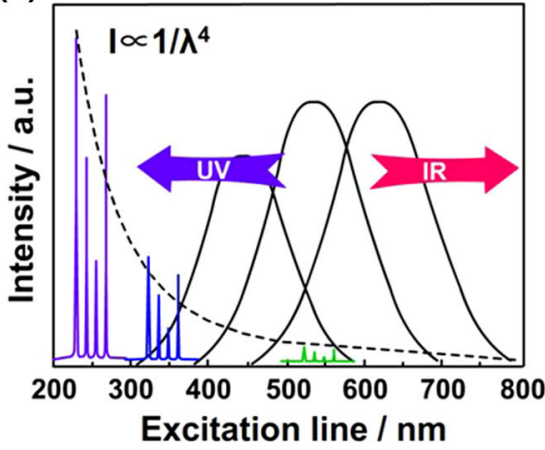

(b)

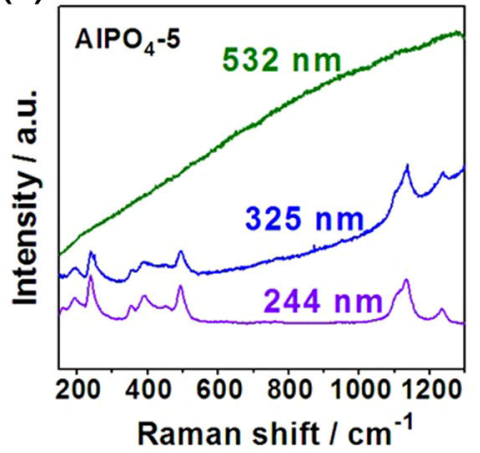

(c)

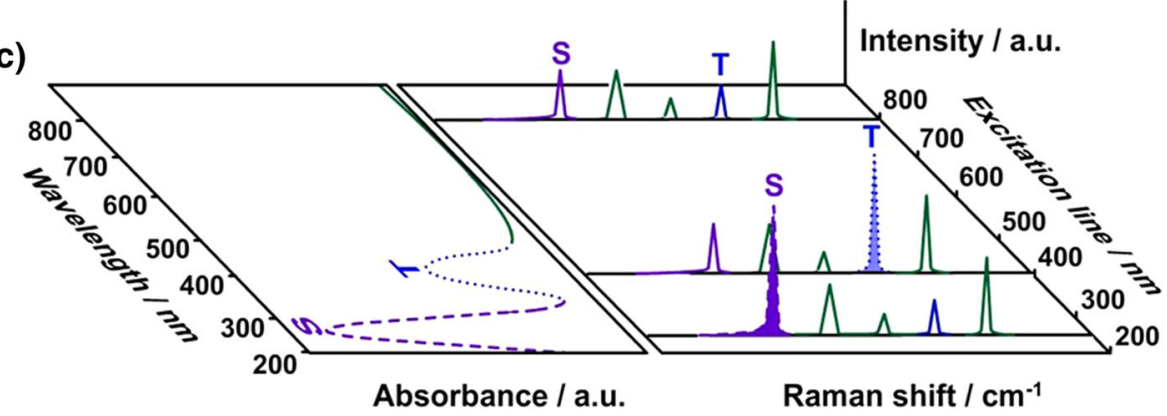


out for many samples. The intensity of Raman scattering is proportional to $\left|\alpha_{\rho \sigma}\right|^{2}$, and the polarizability $\left(\alpha_{\rho \sigma}\right)$ can be expressed by the Kramers-Heisenberg equation [30],

$\left(\alpha_{\rho \sigma}\right)_{f i}=\sum_{r \neq i, f}\left(\frac{\left\langle f\left|\hat{p}_{\rho}\right| r\right\rangle\left\langle r\left|\hat{p}_{\sigma}\right| i\right\rangle}{\Delta E_{r i}-h v_{0}-i \Gamma_{r}}+\frac{\left\langle f\left|\hat{p}_{\sigma}\right| r\right\rangle\left\langle r\left|\hat{p}_{\rho}\right| i\right\rangle}{\Delta E_{r f}+h v_{0}+i \Gamma_{r}}\right)$

In the equation, $v_{0}$ is the frequency of excitation laser, $\Delta E_{\mathrm{ri}}$ stands for the energy difference between the two electronic states $r$ and $i$, while state $f$ is the first excited vibrational energy level. When the laser line $\left(h v_{0}\right)$ is close to an electronic transition $\left(\Delta E_{\mathrm{ri}}\right)$, the polarizability $\left(\alpha_{\rho \sigma}\right)$ would be greatly increased. As a result, the cross section of Raman scattering could be considerably enhanced, and Raman intensity can be increased by several orders of magnitude owing to the resonance Raman effect (Fig. 1c). Since Raman bands associated with different components can be selectively enhanced by excitation at different laser lines according to their electronic transitions, UV resonance Raman spectroscopy is particularly powerful in characterizing the complex solid catalysts in heterogeneous catalysis [24, 25].

In the feature article, we briefly review the recent advances in UV Raman spectroscopic characterization of catalysts and catalytic active sites in our group, including the characterization of transition metal-containing catalytic materials, the synthesis mechanism of zeolites, and the study on the phase transformation of metal oxide photocatalysts. The information obtained by UV Raman spectroscopy is beneficial for the understanding of heterogeneous catalysis.

\subsection{UV Raman Spectroscopic Characterization of Transition Metal-Containing Catalytic Materials}

The isomorphous substitution of the silicon and aluminum in microporous and mesoporous materials with transition metal elements is one of the most effective ways to modify the physicochemical properties of microporous and mesoporous materials [31]. Transition metal-containing microporous and mesoporous materials such as TS-1, Ti-MCM41 and Fe-ZSM-5 have been successfully used in a number of catalytic oxidation processes [32-35]. The catalytic performance of these transition metal-containing materials depends largely on their composition and structure. A deep understanding of the active sites and the formation mechanism in these materials is helpful for the development of catalysts with high selectivity and activity [36, 37]. However, due to the low concentration of transition metal ions $(<2 \%)$, it is difficult to obtain definite information on the transition metal ions in these materials [31], such as their coordination environments and distributions. Since there is usually a UV charge transfer transition between the framework oxygen ion and the framework transition metal ion, e.g. $220 \mathrm{~nm}$ for TS-1, $250 \mathrm{~nm}$ for Fe-ZSM-5, and $280 \mathrm{~nm}$ for V-MCM-41 (Fig. 2a) [25], UV resonance Raman spectroscopy is considered as a powerful technique for the characterization of transition-metal containing materials. The information about transition metal species can be selectively enhanced and obtained by UV resonance Raman spectroscopy.

Figure $2 b$ shows the Raman spectra of silicalite- 1 and TS-1 excited at different laser lines. With the charge transfer transition of TS-1 at $220 \mathrm{~nm}$ excited by the $244 \mathrm{~nm}$ laser, three new bands at 490, 530, and $1125 \mathrm{~cm}^{-1}$ are observed in the UV Raman spectrum of TS- 1 excited at $244 \mathrm{~nm}$. None of these bands is clearly observed in the Raman spectra excited at 325 and $488 \mathrm{~nm}$ due to the low concentration of titanium ion and non-resonance excitation. There is no doubt that the appearance of these bands are associated with framework titanium but not with silicalite1 [38]. The three resonance-enhanced Raman bands are attributed to a local unit of $\left[\mathrm{Ti}(\mathrm{OSi})_{4}\right]$ in TS-1, denoted by Ti-O-Si. The bands at 490 and $530 \mathrm{~cm}^{-1}$ are assigned to the bending and symmetric stretching vibration of the framework Ti-O-Si species, respectively, while the band at $1,125 \mathrm{~cm}^{-1}$ is ascribed to the asymmetric stretching vibration of Ti-O-Si [36, 39]. Similar phenomenon was observed for iron-containing microporous material $\mathrm{Fe}$ ZSM-5 (Fig. 2c). In comparison with ZSM-5, the UV Raman spectrum of Fe-ZSM-5 excited at $244 \mathrm{~nm}$ exhibits new bands at 516, 1016, 1115, and $1165 \mathrm{~cm}^{-1}$. The intensities of Raman bands at 516, 1115 , and $1165 \mathrm{~cm}^{-1}$ become considerably weaker when it is excited at $325 \mathrm{~nm}$ and the three Raman bands almost disappear once the excitation line shifts to $532 \mathrm{~nm}$. Notably, the band at $1,016 \mathrm{~cm}^{-1}$ is observed regardless of excitation line. Periodic DFT calculation indicates that the resonanceenhanced bands at 516 and $1,115 \mathrm{~cm}^{-1}$ are attributed to the symmetric and asymmetric stretching vibrations of the framework $\mathrm{Fe}-\mathrm{O}-\mathrm{Si}$ species in tetrahedral coordination, and the resonance Raman band at $1,165 \mathrm{~cm}^{-1}$ is ascribed to the asymmetric stretching vibrations of the framework $\mathrm{Fe}-\mathrm{O}-\mathrm{Si}$, driven by the stretching of four neighboring framework $\mathrm{Si}-\mathrm{O}-\mathrm{Si}$ bonds, while the non-resonance Raman band at $1,016 \mathrm{~cm}^{-1}$ is associated with the vibration of Si-O-Si bond near framework iron [40]. Therefore, the framework titanium and iron species with low content was unambiguously identified by UV resonance Raman spectroscopy [38-41].

Besides the microporous materials, the titanium and ironcontaining mesoporous materials were also studied by UV resonance Raman spectroscopy excited at $244 \mathrm{~nm}$ [42, 43]. Ti-MCM-41 shows a resonance-enhanced Raman band at $1,110 \mathrm{~cm}^{-1}$, which is $15 \mathrm{~cm}^{-1}$ lower than that of TS- 1 (Fig. 3). Similarly, the resonance Raman band at $1,090 \mathrm{~cm}^{-1}$ for Fe-SBA-15 is also lower than that at $1,115 \mathrm{~cm}^{-1}$ for $\mathrm{Fe}-$ 
Fig. 2 a Charge transfer transition between oxygen and transition metal ions in the framework of molecular sieves; b Raman spectra of TS-1 and silicalite-1 excited at 244, 325 and $488 \mathrm{~nm}$ [38, 39]; c Raman spectra of Fe-ZSM-5 and ZSM5 excited at 244,325 , and $532 \mathrm{~nm}[40]$ (a)

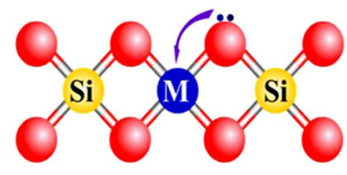

$\mathrm{O}(2 \mathrm{p}) \stackrel{220 \mathrm{~nm}}{\longrightarrow} \mathrm{Ti}(3 \mathrm{~d})$

$\mathrm{O}(2 \mathrm{p}) \stackrel{250 \mathrm{~nm}}{\longrightarrow} \mathrm{Fe}(3 \mathrm{~d})$

$\mathrm{O}(2 \mathrm{p}) \stackrel{280 \mathrm{~nm}}{\longrightarrow} \vee(3 \mathrm{~d})$ (b)

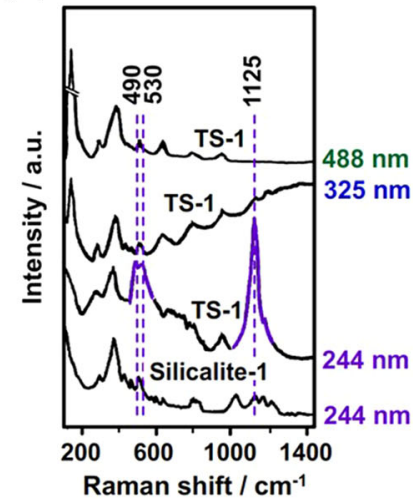

(c)

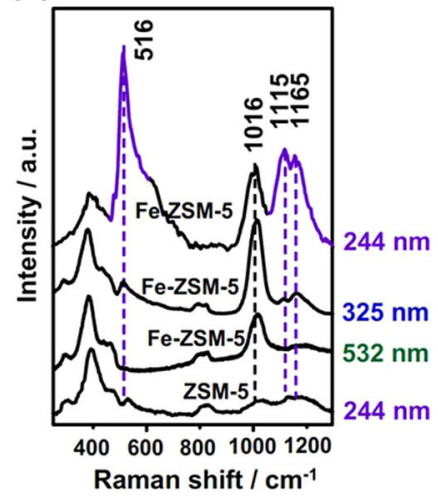

ZSM-5 (Fig. 3). The differences in wavenumber indicate the differences in coordination environments of metal ions in the two kinds of materials. The metal ions in microporous materials are fixed in the rigid framework sites, while that in mesoporous materials are relatively flexible. When the coordination environment becomes much more flexible, the resonance Raman band for $\mathrm{Ti} / \mathrm{SiO}_{2}$ shifts to $1,085 \mathrm{~cm}^{-1}$, which is $25 \mathrm{~cm}^{-1}$ lower than that of Ti-MCM-41 (Fig. 3) [44]. Therefore, the wavenumber of resonance-enhanced Raman band can be used as a figure of merit in assessing the coordination environment of metal ion in microporous and mesoporous materials and to discuss the structure-performance relationship [12].

\subsection{UV Raman Spectroscopic Study on the Synthesis} Mechanism of Zeolites

Although numerous zeolites (e.g. Fe-ZSM-5, X zeolite) have been successfully synthesized and used in chemical processes [31,35], understanding the formation mechanism of zeolite is still all-important for the rational design and synthesis of new zeolites. Several assembly mechanisms have been proposed by scientists since the 1960s [45], including the growth from soluble and pre-assembled units [46-48], the autocatalytic nucleation [49, 50] and solidliquid interfacial nucleation mechanism [51, 52] etc. However, it's very difficult to study the detailed formation mechanism of zeolite due to the extreme complexity of hydrothermal crystallization [51]. Most studies were carried out by ex situ techniques, namely, the hydrothermal reaction is quenched for sample analysis. This may cause dramatic and undeterminable structural changes. In situ characterization under working conditions is an ideal method to monitor the entire process of zeolite synthesis. However, the exploration of in situ characterization for zeolite synthesis is relatively lacking [53]. Due to the low Raman scattering cross section of water, Raman spectroscopy is considered as a suitable technique to in situ study the synthesis mechanism of zeolite under hydrothermal condition. Raman spectroscopy can provide the information on the nucleation and crystal growth in the synthesis process, especially the information about the evolution of species in the early stage, which is crucial for the understanding of zeolite assembly mechanism [54, 55]. The power of in situ visible Raman spectroscopy has been demonstrated by Weckhuysen and co-workers in studying the synthesis mechanism of aluminophosphate molecular sieves [56, 57]. However, visible Raman spectroscopy often fails to work due to the strong fluorescence interference caused by template decomposition under hydrothermal condition. As mention above, UV Raman spectroscopy can address this problem very well, and the sensitivity can be obviously improved, especially under the condition of resonance excitation. These advantages make UV Raman spectroscopy an excellent technique to in situ study the synthesis mechanism of molecular sieves [58-61] and investigate the assembly mechanism of transition metal-containing zeolites [62] since the information about transition metal ion is hard to obtain due to the low concentration of transition metal ion incorporated into zeolite framework [63, 64].

UV Raman spectroscopy with the excitation lines at 325 and $244 \mathrm{~nm}$ were used to study the synthesis mechanism of Fe-ZSM-5 (Fig. 4a, b). As for the initial precursor, the Raman bands assigned to five-, six-membered silicate rings and $\mathrm{Fe}(\mathrm{OSi})_{4}$ species are observed in the UV Raman spectra. Upon hydrothermal treatment, a weaker Raman band at $378 \mathrm{~cm}^{-1}$ attributed to the MFI structure is detected in the $325 \mathrm{~nm}$ excited Raman spectra of the sample hydrothermalized for $6 \mathrm{~h}$. Such a band appears much later when the excitation line is at $244 \mathrm{~nm}$. Beside, the Raman band at $983 \mathrm{~cm}^{-1}$ associated with the $\mathrm{Fe}(\mathrm{OSi})_{4}$ species in flexible coordination gradually becomes sharp and shifts to a higher frequency with the synthesis time increasing. However, the hypsochromic shift rate of the band at $983 \mathrm{~cm}^{-1}$ becomes much slower when the 
Fig. 3 Characteristic Raman frequencies in UV Raman spectra of titanium and ironcontaining microporous and mesoporous materials and the schematic description of the coordination environments of metal ions

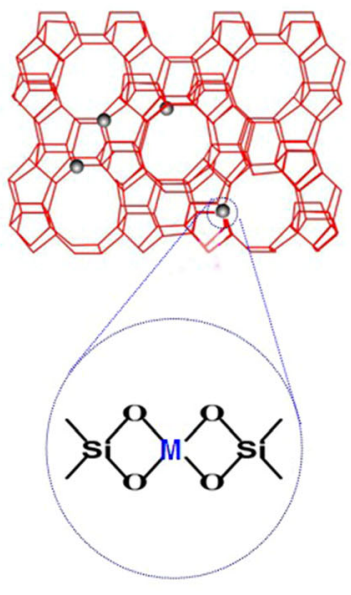

TS-1: $1125 \mathrm{~cm}^{-1}$

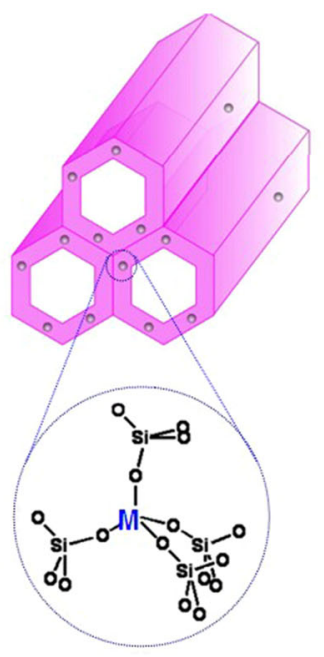

Ti-MCM-41: $1110 \mathrm{~cm}^{-1}$

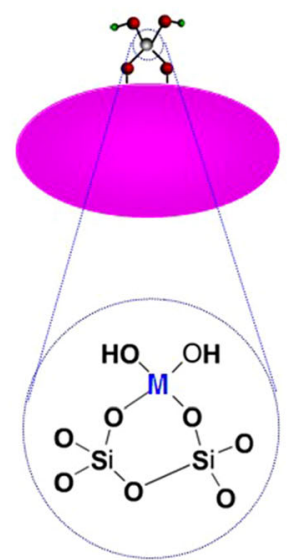

$\mathrm{Ti} / \mathrm{SiO}_{2}: 1085 \mathrm{~cm}^{-1}$

\section{Fe-ZSM-5: $1115 \mathrm{~cm}^{-1} \quad$ Fe-SBA-15: $1090 \mathrm{~cm}^{-1}$} Rigid Flexible (a)

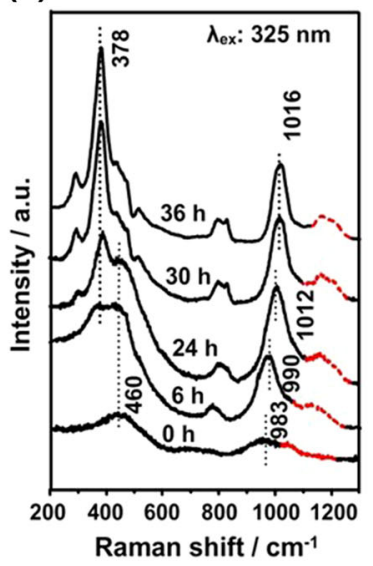

(b)

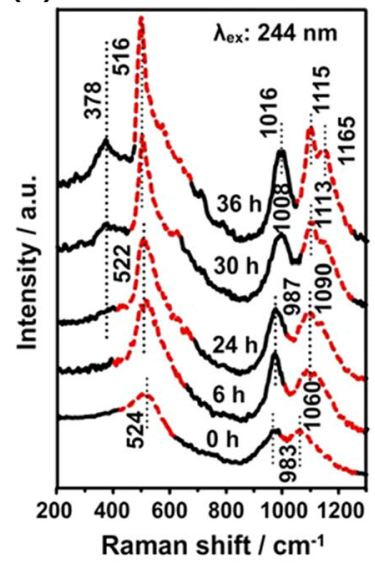

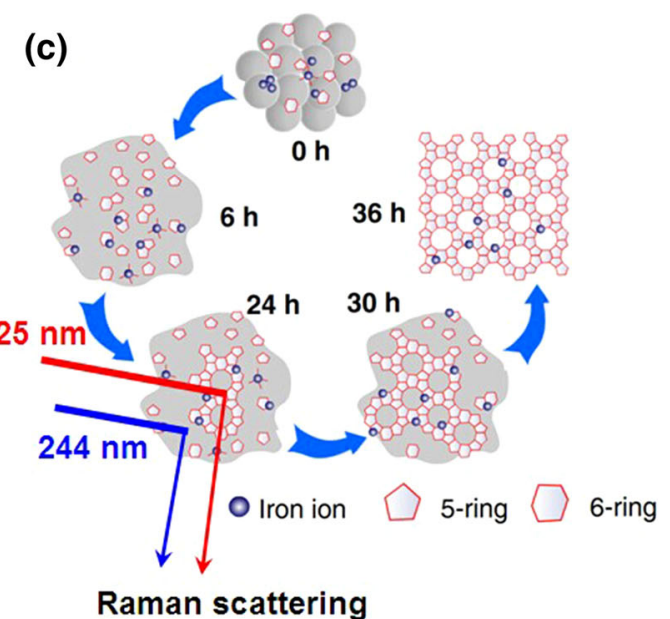

Fig. 4 UV Raman spectra of Fe-ZSM-5 (Si/Fe = 152) at different crystallization stages excited at $325 \mathrm{~nm}(\mathbf{a})$ and $244 \mathrm{~nm}(\mathbf{b})$; c A proposed scheme for the formation mechanism of Fe-ZSM-5 [62]

excitation line shifts from 325 to $244 \mathrm{~nm}$. Since all the samples at various crystallization stages show strong absorption below $300 \mathrm{~nm}$, UV Raman spectroscopy excited with $244 \mathrm{~nm}$ laser provides the information mainly from the surface region while that excited with $325 \mathrm{~nm}$ laser provides the information mainly from the bulk of sample particles (Fig. 4c). These results definitely suggest that the formation of Fe-ZSM-5 structure is initiated at the core of sample particles, then the crystallization develops from inside to outside, which was also confirmed by HRTEM.
Therefore, we proposed the synthesis mechanism of FeZSM-5 shown in Fig. 4c [62].

Although the assembly mechanism of faujasite zeolite from ring units has been studied by numerous techniques, such as NMR and Raman spectroscopy [65, 66], the detailed chemical connection of the ring units remains unclear. Besides, the relevance between the species in solution and the nature of solid phases should be further addressed. To gain a deeper understanding of the formation mechanisms of zeolite $\mathrm{X}$ and other molecular sieves, we 
Fig. 5 a A schematic diagram of the experimental apparatus used for in situ UV Raman spectroscopic studies of hydrothermal reactions (1); In situ UV Raman cell for liquid (2) and solid (3) phase study; b In situ UV Raman spectra of solid phase of zeolite $\mathrm{X}$ synthesis at $373 \mathrm{~K}\left(\lambda_{\text {ex }}\right.$ : $325 \mathrm{~nm}$ ); c Plots of intensities of the bands at $380,514,575$, and $774 \mathrm{~cm}^{-1}$ as a function of time; $\mathbf{d}$ A proposed scheme for the formation mechanism of zeolite X [58] (a)

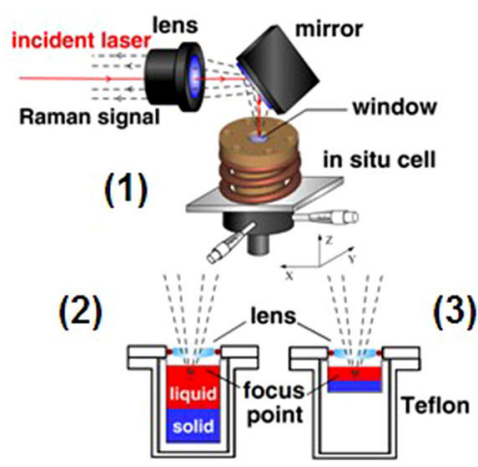

(c)

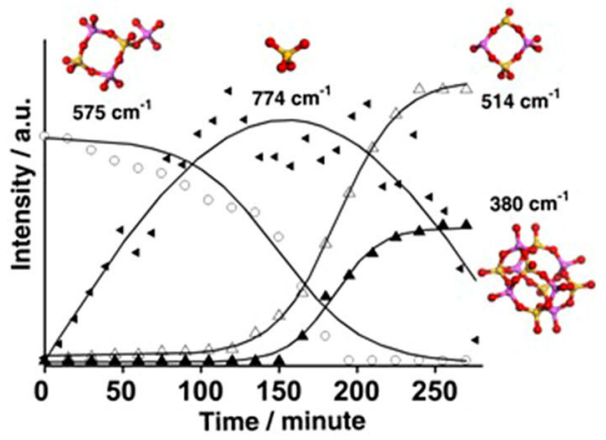

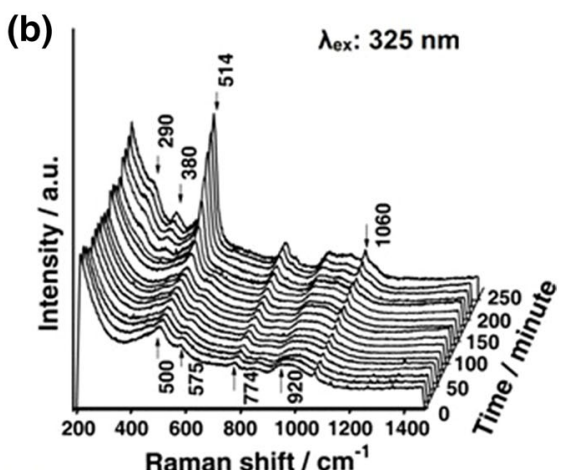

(d)

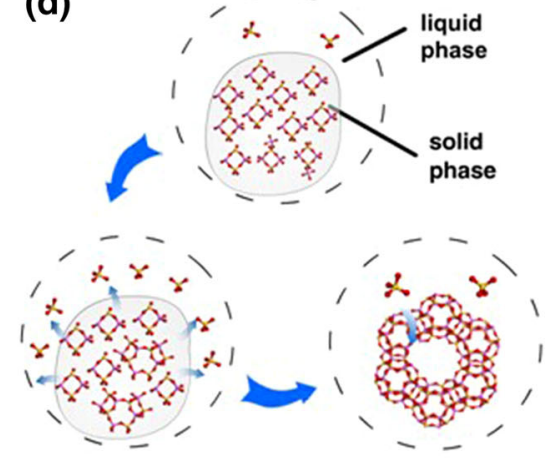

have developed in situ UV Raman spectroscopy to observe the hydrothermal reactions directly [58-60].

With the home-made in situ UV Raman cells with different depth (Fig. 5a) [58], both the solid and liquid phase under hydrothermal conditions were investigated. The liquid phase during the synthesis process of zeolite $\mathrm{X}$ is dominated by monomeric silicate species with the characteristic Raman bands at 774 and $920 \mathrm{~cm}^{-1}$ [65]. While the initial gel is composed of four-membered rings and a small amount of branched derivatives, with the featured Raman bands at 500 and $575 \mathrm{~cm}^{-1}$ [58, 67], respectively (Fig. 5b). These bands show very different behaviors in the intensity as a function of time (Fig. 5c). In the early stage of hydrothermal process, the band at $774 \mathrm{~cm}^{-1}$ becomes strong due to the depolymerization of amorphous precursors into monomeric silicate species. While the intensity of the band continuously decreases in the late stage due to the continuous consumption of monomeric silicate species for the construction of zeolite $\mathrm{X}$ framework. As for the band at $500 \mathrm{~cm}^{-1}$, with the hydrothermal synthesis proceeding, it gradually becomes prominent and gradually shifts to a higher wavenumber at $514 \mathrm{~cm}^{-1}$. Different from the band at $500 \mathrm{~cm}^{-1}$, the band at $575 \mathrm{~cm}^{-1}$ becomes weak with increasing crystallization. Interestingly, the band disappears when the characteristic bands at 298, 380 and $514 \mathrm{~cm}^{-1}$ associated with the framework of zeolite $\mathrm{X}$ appear [54]. These results indicates that four-membered rings and a small amount of branched derivatives are the main species in the early stage of nucleation and the branched derivative is a key intermediate for the formation of zeolite X.

Based on the in situ Raman results, we proposed the assembly mechanism of zeolite $\mathrm{X}$ with new intermediate species [58], and the assembly mechanism is schematically shown in Fig. 5d.

\subsection{In situ (UV) Raman Spectroscopic Characterization of Catalytic Active Sites and Study of Reaction Mechanisms}

As a highly active and selective catalyst, TS- 1 has been widely used in a number of oxidation reactions with $\mathrm{H}_{2} \mathrm{O}_{2}$ as oxidant under mild conditions [32, 33, 37]. However, there are still many issues under debate, such as what's the exact nature of the active site $[36,37,68,69]$ and the reaction pathways [70-73]. Recently, we have conducted a thorough investigation of the active titanium species in TS1 zeolite [74]. Besides the framework titanium species identified by UV Raman spectroscopy excited at $244 \mathrm{~nm}$, another titanium species with octahedral coordination $\left(\mathrm{TiO}_{6}\right)$ was confirmed by UV Raman spectroscopy with the excitation line at $266 \mathrm{~nm}$ (Fig. 6a). And the roles of two titanium species in the propylene epoxidation reaction were studied by in situ UV Raman spectroscopy excited at $325 \mathrm{~nm}$ (Fig. 6b). Both two kinds of titanium species can react with $\mathrm{H}_{2} \mathrm{O}_{2}$ to form the $\eta^{2}$ side-on Ti-peroxo species 
Fig. 6 a Two kinds of titanium species characterized by UV resonance Raman spectroscopy; b In situ UV Raman cell for characterizing the propylene epoxidation reaction; $\mathbf{c}$ The proposed pathway during the propylene oxidation on the two kinds of active centers [74] (a)

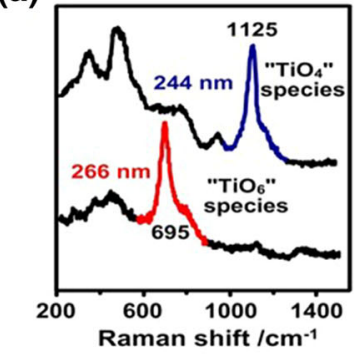

(b)

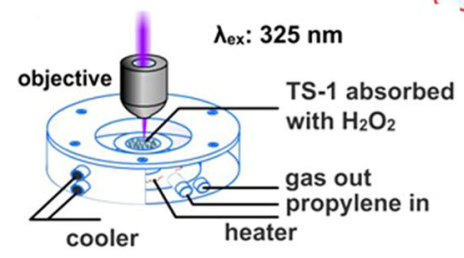

(c)

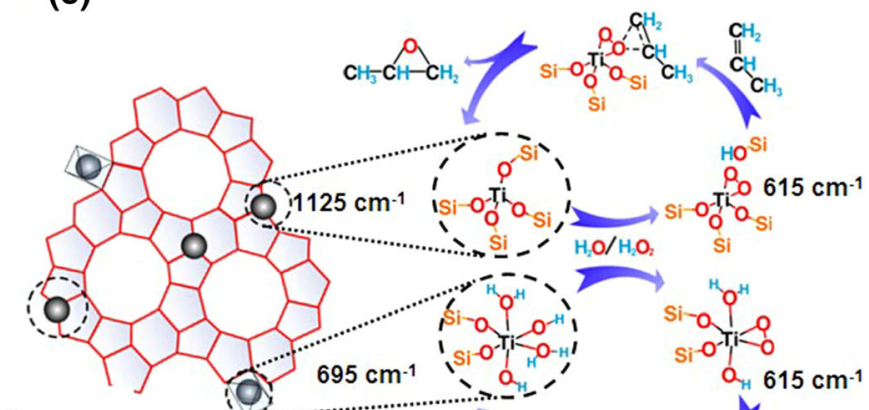

with the characteristic band at $615 \mathrm{~cm}^{-1}$, which is the active intermediate for the epoxidation of propylene [75]. Propylene oxide was detected after interaction with propylene, however, the 1,2-propanediol byproduct was also observed for the catalyst with " $\mathrm{TiO}_{6}$ " species. Notably, the Raman band at $1,125 \mathrm{~cm}^{-1}$ attributed to " $\mathrm{TiO}_{4}$ " species recovers after the catalytic cycle, while the Raman band at $695 \mathrm{~cm}^{-1}$ attributed to " $\mathrm{TiO}_{6}$ " species is not recovered. This can be explained that the " $\mathrm{TiO}_{6}$ " species could be deactivated by the diol byproduct. Therefore, we proposed the possible pathway during the propylene oxidation on the two kinds of active centers (Fig. 6c) [74]. The finding of $\mathrm{TiO}_{6}$ species is significant not only for the reveal of the mechanism of side reaction, but also for the improvement of framework titanium amount. Recently, we have increased the concentration of the framework titanium in TS- 1 zeolite by a factor of 1.5 by lowering the $\mathrm{pH}$ value of the synthesis gel [76].

Fe/ZSM-5 catalysts have attracted much attention because of their unique properties in oxidative dehydrogenation of alkanes [77], selective catalytic reduction of $\mathrm{NO}_{x}$ with ammonia [78] and direct catalytic $\mathrm{N}_{2} \mathrm{O}$ decomposition [35, 79]. More interestingly, with $\mathrm{N}_{2} \mathrm{O}$ as the oxidant, the " $\alpha$-oxygen" species can be formed on the Fe/ ZSM-5 catalysts, which shows high activity and selectivity in the hydroxylation of methane to methanol and benzene to phenol at room temperature [80]. However, due to the complexity of iron species in Fe/ZSM-5, there are still many controversies in the peculiar active sites and the property of $\alpha$-oxygen. Different iron species (e.g., mononuclear [81, 82], binuclear Fe sites [83, 84], oligo-nuclear Fe clusters $[85,86]$ ) have been proposed to be the active sites for $\mathrm{N}_{2} \mathrm{O}$ decomposition and different transition states of oxygen species (e.g., peroxide [87, 88], superoxides [87, 88], $\mathrm{O}-*-\mathrm{O}$ species [89]) during $\mathrm{N}_{2} \mathrm{O}$ decomposition on
Fe/ZSM-5 have been proposed based on kinetic and calculation methods. Although Mössbauer and ESR spectroscopy have been used for the study of peculiar active sites [90, 91], direct spectroscopic evidence about the nature of the active sites and the transition-state oxygen species during $\mathrm{N}_{2} \mathrm{O}$ decomposition are absent, especially under working conditions. Over the past years, in situ resonance Raman spectroscopy has been used to study the peculiar active sites and the property of $\alpha$-oxygen in iron containing zeolites and the catalytic mechanisms by our group (Fig. 7a) [92].

As for the Fe/ZSM- 5 catalyst, after the high-temperature pretreated sample exposed to $\mathrm{N}_{2} \mathrm{O}$ at $523 \mathrm{~K}$, the Raman band at $867 \mathrm{~cm}^{-1}$ assigned to the peroxo species bridged on a binuclear iron site [92-94] is observed in the resonance Raman spectrum excited at $605 \mathrm{~nm}$. The active oxygen species can react with benzene at room temperature, with three characteristic Raman bands at 643, 896, and $1,228 \mathrm{~cm}^{-1}$ associated with $\mathrm{Fe}(\mathrm{III})$-phenolate $[95,96]$ observed. Based on these results, we proposed a possible reaction pathway of $\mathrm{N}_{2} \mathrm{O}$ decomposition and benzene to phenol shown in Fig. 7b [88]. Besides, the effect of extraframework aluminum/gallium [97-99], the promotional effect of $\mathrm{NO}$ [100] and the inhibiting effect of $\mathrm{H}_{2} \mathrm{O}$ on $\mathrm{N}_{2} \mathrm{O}$ decomposition over Fe/ZSM-5 catalyst [101] were well studied by our group with the in situ resonance Raman spectroscopy.

Recently, we have further investigated the structure of active iron site and active oxygen species in Fe/ZSM-35 material by in situ resonance Raman spectroscopy combined with Mössbauer spectroscopy and DFT calculations [102]. The active iron site in Fe/ZSM-35 for $\mathrm{N}_{2} \mathrm{O}$ decomposition is an $\mathrm{Fe}_{2}(\mu-\mathrm{O})$ site, characterized by a Raman band at $875 \mathrm{~cm}^{-1}$ [102]. Different from the peroxo species formed on Fe/ZSM-5 catalyst, the $\mathrm{Fe}_{2}(\mu-\mathrm{O})_{2}$ site with the 
Fig. 7 a In situ Raman cell for gas-solid reaction; $\mathbf{b} \mathrm{A}$ schematic description of the reaction pathway of $\mathrm{N}_{2} \mathrm{O}$ decomposition and benzene to phenol on Fe/ZSM-5 at room temperature; $\mathbf{c}$ The structure and corresponding Raman band of active oxygen species on $\mathrm{Fe} /$ ZSM-5 and Fe/ZSM-35 [92, 102]

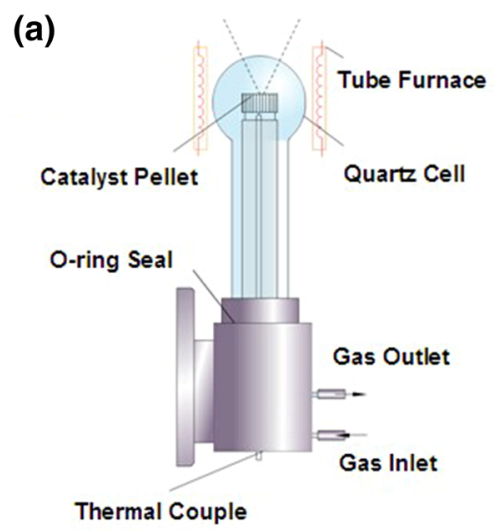

(b)
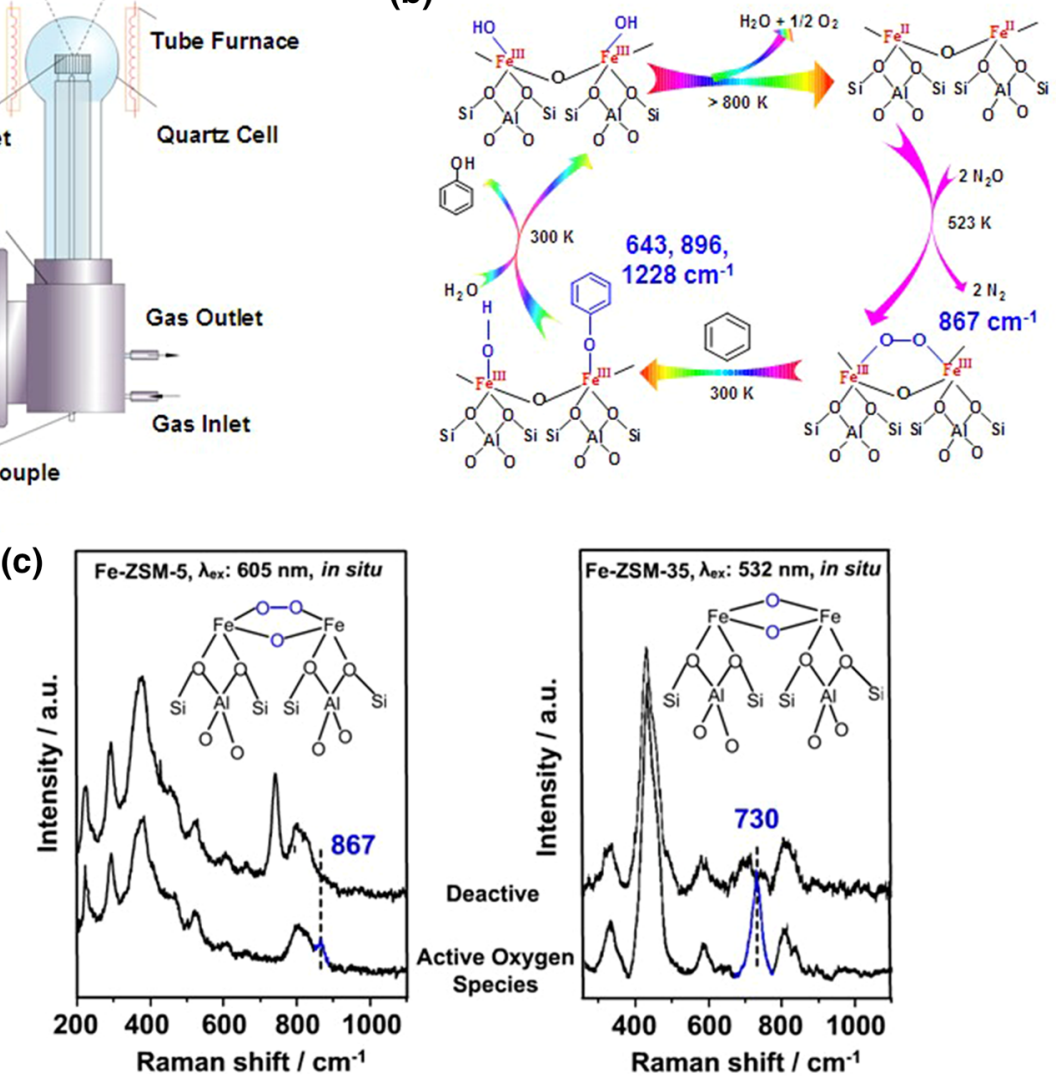

featured Raman band at $730 \mathrm{~cm}^{-1}$ is formed on Fe/ZSM35 catalyst upon $\mathrm{N}_{2} \mathrm{O}$ reacting with the $\mathrm{Fe}_{2}(\mu-\mathrm{O})$ site (Fig. 7c) [61, 102]. The result indicates that the topology of iron containing zeolite has a great influence on the active center and then affects the catalytic performance.

\subsection{UV Raman Spectroscopic Study on the Phase Transformation of Metal Oxides}

It's known that polymorphism is a common phenomenon for most metal oxides. Due to the difference in microstructure, different crystalline phases show the large differences in the physical and chemical properties, such as the catalytic performance [103-105]. As catalytic reactions take place on the surface of metal oxide catalysts, catalytic performance is closely related to the surface phase structure of catalyst. However, it's difficult to characterize their surface phase structures clearly since most techniques are bulk region sensitive. For example, XRD is a bulk sensitive technique due to the long-ranged characteristic of diffraction. HRTEM can provide the structural information from the surface region, but it has the limitations of inconvenience and one-sidedness. In the study of phase transformation of $\mathrm{ZrO}_{2}$ material, we have found that UV Raman spectroscopy is a surface region sensitive technique for the system with strong absorption in the UV region [106, 107]. Over the past years, we have studied the phase transformation of $\mathrm{TiO}_{2}$ and $\mathrm{Ga}_{2} \mathrm{O}_{3}$ photocatalytic materials by UV Raman spectroscopy and investigated the relationship between the surface phase and photocatalytic performance [104, 108-112].

Compared with visible Raman spectroscopy excited with $532 \mathrm{~nm}$ laser, UV Raman spectroscopy excited with $325 \mathrm{~nm}$ laser mainly provides the information from the surface region of $\mathrm{TiO}_{2}$ material due to the strong absorption of anatase and rutile $\mathrm{TiO}_{2}$ at $325 \mathrm{~nm}$ (Fig. 8a). Visible Raman spectroscopic characterization indicates that a small amount of anatase phase is transformed into rutile phase when the sample is calcined at $823 \mathrm{~K}$ and the phase transformation is accomplished when the calcination temperature is at or above $1,023 \mathrm{~K}$ (Fig. 8b). However, UV Raman spectroscopic characterization indicates that no rutile phase is formed until the calcined temperature is elevated to $973 \mathrm{~K}$ and the anatase phase is completely transformed into rutile phase only for the sample calcined at $1,073 \mathrm{~K}$ (Fig. 8c). The disagreements between UV and visible Raman spectroscopy suggest that the crystalline phase in the surface region is usually different from that in 
Fig. 8 a UV-visible diffuse reflectance spectra of anatase and rutile $\mathrm{TiO}_{2} ; \mathbf{b}$ Visible Raman spectra of $\mathrm{TiO}_{2}$ calcined at different temperatures excited at $532 \mathrm{~nm}$; c UV Raman spectra of $\mathrm{TiO}_{2}$ calcined at different temperatures excited at $325 \mathrm{~nm}$; d A proposed scheme for the phase transformation of $\mathrm{TiO}_{2}$ with increasing calcination temperature [108]
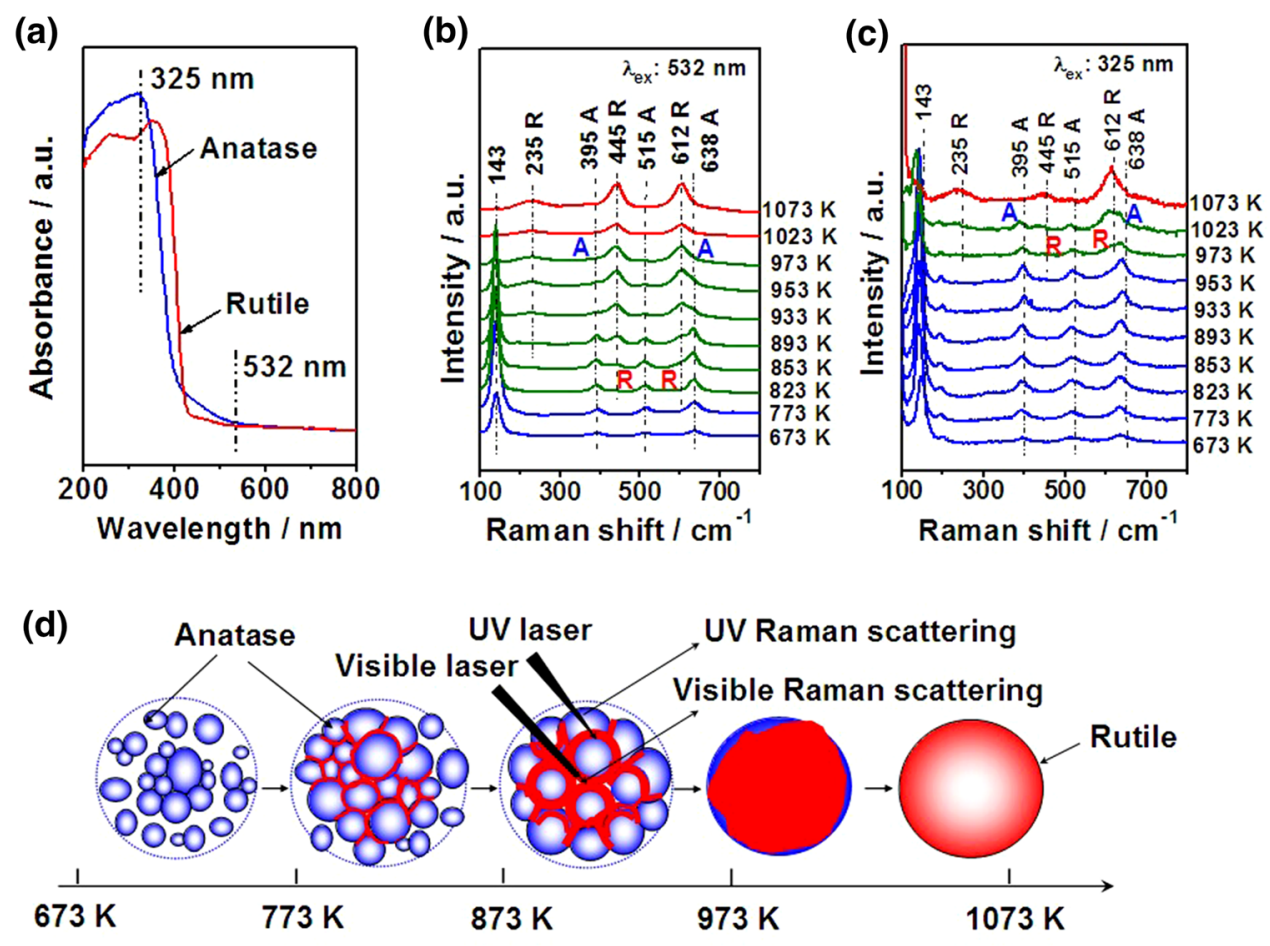

the bulk during the phase transformation of $\mathrm{TiO}_{2}$ material. Based on the above results, we proposed that the phase transformation of agglomerated $\mathrm{TiO}_{2}$ with the size in $15-40 \mathrm{~nm}$ from anatase to rutile starts in the bulk and then develops to the surface of agglomerated particles (Fig. 8d) [108].

Besides, we have investigated the effect of nanoparticle size on the outer/inner phase transformation of $\mathrm{TiO}_{2}$ material by UV Raman spectroscopy [109]. Particle size is found to be the critical parameter determining the onset transition temperature and nucleation performance. The transformation temperature increases with the increase of initial particle size. Rutile nucleates at the interfaces of contacting anatase grains with the size smaller than $60 \mathrm{~nm}$, while the free surface, interface, and bulk are all likely to work as rutile nucleation sites for particles larger than $60 \mathrm{~nm}$.

Due to the excellent photocatalytic performance of $\mathrm{TiO}_{2}$ material, photocatalytic $\mathrm{H}_{2}$ evolution reaction were performed on the above-mentioned $\mathrm{TiO}_{2}$ samples with different bulk and surface crystalline phases [104]. Interestingly, the $\mathrm{TiO}_{2}$ samples calcined at $973-1,023 \mathrm{~K}$ with both phases exposed on the surface exhibit the highest photocatalytic activity no matter the activity is normalized by specific surface area or not (Fig. 9a). Thus, the highest photocatalytic activity of the samples calcined at 973-1,023 K may be attributed to the formation of the surface phase junctions between anatase nanoparticles and rutile particles.
The opinion was demonstrated by fabrication of the surface anatase-rutile phase junction on rutile $\mathrm{TiO}_{2}$ particles with a wet-impregnation method. Figure $9 \mathrm{~b}$ shows the UV Raman spectra of $\mathrm{TiO}_{2}(\mathrm{~A}) / \mathrm{TiO}_{2}(\mathrm{R})$-n samples excited at $325 \mathrm{~nm}$. With a small amount of anatase loaded on the surface of rutile $\mathrm{TiO}_{2}$, the $\mathrm{TiO}_{2}(\mathrm{~A}) / \mathrm{TiO}_{2}(\mathrm{R})-1$ and -2 samples show much higher photocatalytic activities than pure rutile $\mathrm{TiO}_{2}$ (Fig. 9c). And the photocatalytic activity of $\mathrm{TiO}_{2}(\mathrm{~A}) / \mathrm{TiO}_{2}(\mathrm{R})-3$ sample is about four times greater than that of pure rutile $\mathrm{TiO}_{2}$. This enormous increase in photocatalytic activity can be attributed to the formation of the surface anatase-rutile phase junction. As the amount of loaded anatase further increases, the photocatalytic activity of $\mathrm{TiO}_{2}(\mathrm{~A}) / \mathrm{TiO}_{2}(\mathrm{R})-4$ sample is decreased somewhat because the surface of rutile $\mathrm{TiO}_{2}$ may be fully covered by anatase nanoparticles, which decreases the amount of anatase-rutile phase junction exposed on the surface of $\mathrm{TiO}_{2}$ particle. Therefore, we proposed the concept that the photocatalytic activity can be enhanced by the surface phase junction of semiconductor catalysts [104]. Recently, our time-resolved IR spectroscopic study indicates that the electron is transferred from anatase to rutile in the $\mathrm{TiO}_{2}$ sample with the surface anatase-rutile phase junction [113], which may be responsible for the enhancement of photocatalytic activity.

Besides in photocatalytic $\mathrm{H}_{2}$ evolution, such a concept was furthered confirmed in photocatalytic overall water splitting over $\mathrm{Ga}_{2} \mathrm{O}_{3}$ photocatalysts [112]. $\mathrm{Ga}_{2} \mathrm{O}_{3}$ is a polymorphous material with five kinds of crystalline phases 
Fig. 9 a Photocatalytic $\mathrm{H}_{2}$ evolution activity on $\mathrm{TiO}_{2}$ samples calcined at different temperatures normalized by specific surface area; b UV Raman spectra of $\mathrm{TiO}_{2}(\mathrm{~A}) /$ $\mathrm{TiO}_{2}(\mathrm{R})$-n samples excited at $325 \mathrm{~nm}$; c Photocatalytic $\mathrm{H}_{2}$ evolution activity on $\mathrm{TiO}_{2}(\mathrm{~A}) /$ $\mathrm{TiO}_{2}(\mathrm{R})$-n samples with increasing amount of anatase phase on the surface of rutile $\mathrm{TiO}_{2}$. The anatase contents estimated from XRD and UV Raman spectroscopy for $\mathrm{TiO}_{2}(\mathrm{~A}) / \mathrm{TiO}_{2}(\mathrm{R})-\mathrm{n}$ samples are also displayed [104] (a)

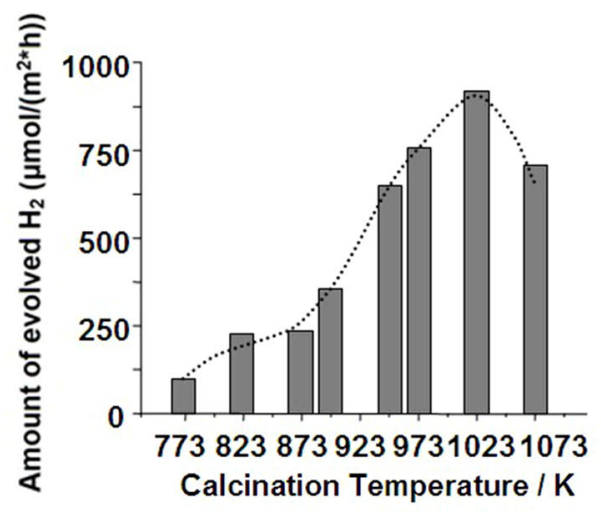

(b)

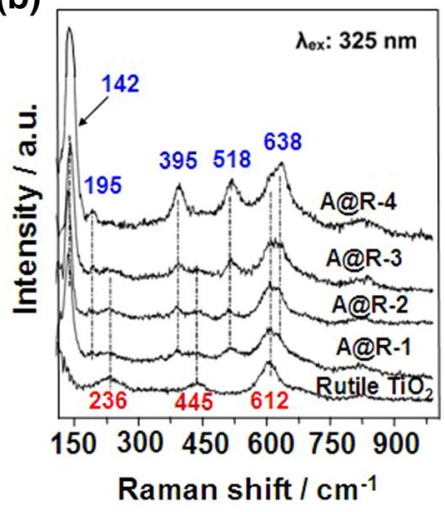

(c)

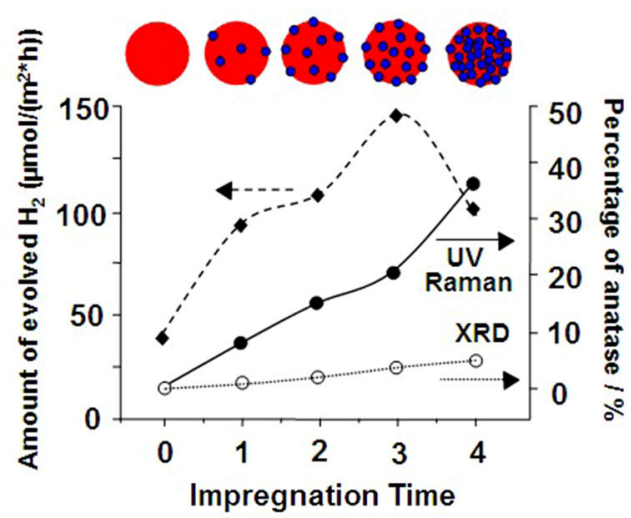

( $\alpha, \beta, \gamma, \delta$, and $\varepsilon$ phases) [114] and has been reported to exhibit the photocatalytic activity on overall water splitting [115]. We investigated the $\alpha$ to $\beta$ phase transformation of $\mathrm{Ga}_{2} \mathrm{O}_{3}$ material by UV Raman spectroscopy with the excitation lines at 266 and $325 \mathrm{~nm}$ (Fig. 10a, b) and XRD technique [111]. Different from that of $\mathrm{TiO}_{2}$, the phase transformation of $\mathrm{Ga}_{2} \mathrm{O}_{3}$ from $\alpha$ phase to $\beta$ phase starts at the surface and then develops to the bulk of single particles. Photocatalytic overall water splitting reaction was performed on the different phase-structured $\mathrm{Ga}_{2} \mathrm{O}_{3}$-based photocatalysts, and the photocatalytic activities are shown in Fig. 10c. All of the photocatalysts can stoichiometrically split water into $\mathrm{H}_{2}$ and $\mathrm{O}_{2}$. The $\mathrm{Ga}_{2} \mathrm{O}_{3}$ sample calcined at $863 \mathrm{~K}$ with both $\alpha$ and $\beta$ phases exposed on the surface shows the highest photocatalytic overall water splitting activity, which is three or seven-fold greater than that of $\alpha$ $\mathrm{Ga}_{2} \mathrm{O}_{3}$ or $\beta-\mathrm{Ga}_{2} \mathrm{O}_{3}$ alone, respectively. While the photocatalytic activity of mechanically mixed $\alpha-\mathrm{Ga}_{2} \mathrm{O}_{3}$ and $\beta$ $\mathrm{Ga}_{2} \mathrm{O}_{3}$ samples is nearly equal to the simple sum of the activities of $\alpha-\mathrm{Ga}_{2} \mathrm{O}_{3}$ and $\beta-\mathrm{Ga}_{2} \mathrm{O}_{3}$ alone. Thus, it is only the surface $\alpha-\beta$ phase junction formed between two different phases that is responsible for the remarkable enhancement in the photocatalytic activity for overall water splitting.

Notably, although the $\alpha-\beta$ phase junction is formed for $\mathrm{Ga}_{2} \mathrm{O}_{3}$ sample calcined at $903 \mathrm{~K}$, it shows photocatalytic activity nearly as low as that of $\beta-\mathrm{Ga}_{2} \mathrm{O}_{3}$. This can be explained by the situation that only the $\beta$ phase is exposed on the surface of $\mathrm{Ga}_{2} \mathrm{O}_{3}$ sample calcined at $903 \mathrm{~K}$ with the $\alpha / \beta$ core/shell structure and the $\alpha-\beta$ phase junction doesn't work. The results suggest that the presence of the $\alpha-\beta$ phase junction and the exposure of both phases on the surface are essential for the enhancement of photocatalytic activity, which is also demonstrated by our recent study on the $\mathrm{ZnGa}_{2} \mathrm{O}_{4}-\beta-\mathrm{Ga}_{2} \mathrm{O}_{3}$ heterojunction [116]. The analysis of band structure indicates that the $\alpha-\beta$ phase junction exhibits type-II band alignment, which is favorable for charge separation. An ultrafast transfer at approximately 3 ps is detected for the $\mathrm{Ga}_{2} \mathrm{O}_{3}$ sample with the surface $\alpha-\beta$ phase junction by transient absorption spectroscopy, which means a much more efficient charge separation due to the existence of surface $\alpha-\beta$ phase junction [112]. In a word, the surface phase structure of metal oxide can be well determined by UV Raman spectroscopy and the proposed concept that the photocatalytic activity can be enhanced by surface phase-junction will open new strategies for the development of efficient photocatalysts for overall water splitting, as well as photoelectronic devices.

As the above examples demonstrated, UV Raman spectroscopy is indeed a very powerful technique for the characterization of catalysts and catalytic active sites. Nowadays, UV Raman spectroscopy with the excitation line continuously-tunable in the UV region and deep UV Raman spectroscopy with the excitation line down to 
Fig. 10 a UV Raman spectra of $\mathrm{Ga}_{2} \mathrm{O}_{3}$ calcined at different temperatures excited at $325 \mathrm{~nm}$; b UV Raman spectra of $\mathrm{Ga}_{2} \mathrm{O}_{3}$ calcined at different temperatures excited at $266 \mathrm{~nm}$; c Photocatalytic overall water splitting activities on $\mathrm{Ga}_{2} \mathrm{O}_{3}$ samples calcined at different temperatures, also on the mechanically mixed sample with a $1: 1$ ratio of $\alpha-\mathrm{Ga}_{2} \mathrm{O}_{3} / \beta$ $\mathrm{Ga}_{2} \mathrm{O}_{3}[111,112]$
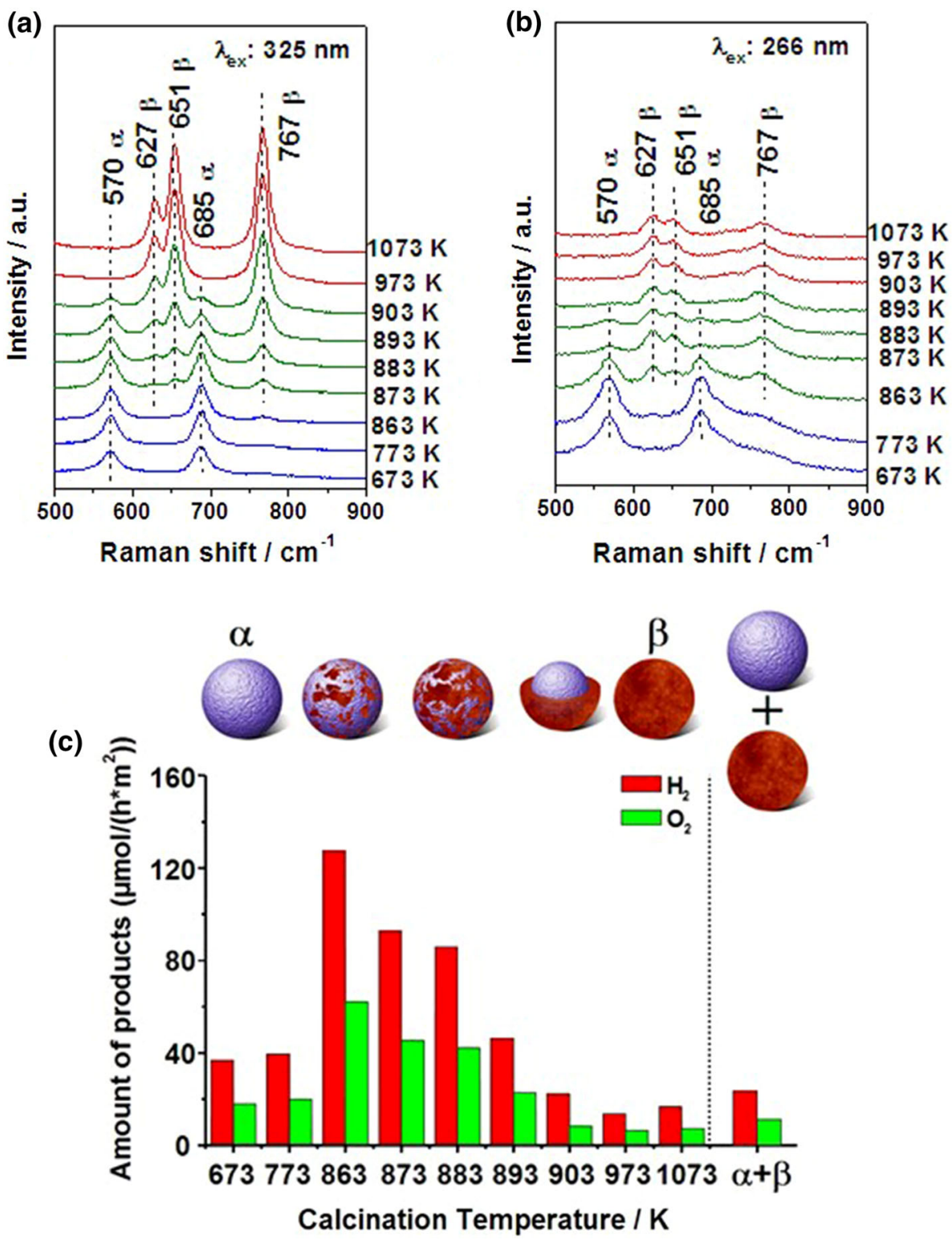

$177.3 \mathrm{~nm}$ have been developed by Peter Stair et al. [24, 117] and our group [118, 119], which is necessary for UV and deep UV resonance Raman spectroscopic study in catalysis. And the primary results show the advantages of these techniques. Since the active centers in catalysis often possess the dimension feature of nanometer to atomic scale, imaging catalysts at working condition has attracted much attention nowadays [120,121]. As a powerful technique, Raman imaging has been used for the preparation and characterization of catalysts [122-124]. However, the spatial resolution is still too low owing to the diffraction limit. One way to overcome this limit is to use an apertureless near-field scanning optical microscope (ANSOM), for which the spatial resolution can be down to several tens of nanometers [125]. Since the sensitivity of UV Raman spectroscopy is much higher than that of visible Raman spectroscopy, it would be better to develop UV-ANSOMRaman spectroscopy for catalyst imaging. To establish the structure-activity/selectivity relationship, operando spectroscopy based on Raman spectroscopy has been developed, allowing monitoring of catalytic systems with simultaneous on-line product analysis under actual reaction conditions [126-131]. However, the excitation line mostly in the visible region limits its applications due to the fluorescence interference and low sensitivity. As mentioned above, these problems can be well addressed by UV Raman spectroscopy. Therefore, it's significant to develop operando spectroscopy based on UV Raman spectroscopy, which may make great breakthroughs in the study of heterogeneous catalysis. 


\section{Conclusion}

Due to the avoidance of fluorescence interference and the improvement of sensitivity, UV Raman spectroscopy has greatly broadened the application of Raman spectroscopy in heterogeneous catalysis. Isolated transition metal species in the framework of molecular sieves can be identified by UV resonance Raman spectroscopy, even at very low concentration. The coordination surroundings of framework transition metal ions in microporous and mesoporous materials can be sensitively detected by UV resonance Raman spectroscopy. The crystallization process of zeolite has been successfully studied by in situ UV Raman spectroscopy, which can sensitively monitor the evolution of precursors and intermediates during the synthesis under working conditions. The reaction mechanisms have been well studied by in situ (UV) Raman spectroscopy, with the interaction information between catalyst and reactant provided. Besides, the surface phase structure of metal oxides can be clearly determined by UV Raman spectroscopy, on this basis, the concept that photocatalytic activity can be enhanced by surface phase junction of semiconductor catalysts was proposed. Undoubtedly, the knowledge obtained from UV Raman spectroscopy will deepen our understanding of catalysis and guide the rational design and synthesis of novel catalytic materials.

Acknowledgments $\mathrm{Can} \mathrm{Li}$ thanks his former students, Guang Xiong, Yi Yu, Ying Li, Keqiang Sun, Keju Sun, Haian Xia, Junying Wang, Meiling Guo, Qiang Guo, Meijun Li, Jing Zhang, Qian Xu and Xiang Wang for their contribution to this work. This work was financially supported by the National Natural Science Foundation of China (NSFC, Grants 21373212).

\section{References}

1. Armor JN (2011) Catal Today 163:3-9

2. Fechete I, Wang Y, Védrine JC (2012) Catal Today 189:2-27

3. Descorme C, Gallezot P, Geantet C, George C (2012) ChemCatChem 4:1897-1906

4. Somorjai GA, McCrea KR, Zhu J (2005) Top Catal 18:157-166

5. Védrine JC (2014) Appl Catal A Gen 474:40-50

6. Hunger M, Weitkamp J (2001) Angew Chem Int Ed 40:2954-2971

7. Zhang WP, Xu ST, Han XW, Bao XH (2012) Chem Soc Rev 41:192-210

8. Zhang SR, Nguyen L, Zhu Y, Zhan SH, Tsung CK, Tao F (2013) Acc Chem Res 46:1731-1739

9. Dixit L, Gerrard DL, Bowley HJ (1986) Appl Spectrosc Rev 22:189-249

10. Brückner A (2003) Catal Rev Sci Eng 45:97-150

11. Fan FT, Xu Q, Xia HA, Sun KJ, Feng ZC, Li C (2009) Chin J Catal 30:717-739

12. Fan FT, Feng ZC, Li C (2010) Acc Chem Res 43:378-387

13. Grunwaldt JD, Schroer CG (2010) Chem Soc Rev 39:4741-4753

14. Smit ED, Swart I, Creemer JF, Hoveling GH, Gilles MK, Tyliszczak T, Kooyman PJ, Zandbergen HW, Morin C, Weckhuysen BM, Groot MF (2008) Nature 456:222-226
15. Panella B, Vargas A, Ferri D, Baiker A (2009) Chem Mater 21:4316-4322

16. Andanson JM, Baiker A (2010) Chem Soc Rev 39:4571-4584

17. Yu ZW, Zheng AM, Wang Q, Chen L, Xu J, Amoureux JP, Deng F (2010) Angew Chem Int Ed 49:8657-8661

18. Blasco T (2010) Chem Soc Rev 39:4685-4702

19. Knözinger H, Mestl G (1999) Top Catal 8:45-55

20. Wachs IE, Roberts CA (2010) Chem Soc Rev 39:5002-5017

21. Li C, Stair PC (1996) Stud Surf Sci Catal 101:881-890

22. Stair PC, Li C (1997) J Vac Sci Technol A 15:1679-1684

23. Stair PC (2007) Adv Catal 51:75-98

24. Kim HS, Kosuda KM, Duyne RPV, Stair PC (2010) Chem Soc Rev 39:4820-4844

25. Li C (2003) J Catal 216:203-212

26. Chase DB (1986) J Am Chem Soc 108:7485-7488

27. Porterfield DR, Campion A (1988) J Am Chem Soc 110:408-410

28. Asher SA, Johnson CR (1984) Science 225:311-313

29. Asher SA (1993) Anal Chem 65:59-66

30. Long DA (2002) The Raman effect: a unified treatment of the theory of Raman scattering by molecules. John Wiley \& Sons Ltd., Chichester

31. Hartmann M, Kevan L (1999) Chem Rev 99:635-663

32. Taramasso M, Perego G, Notari B (1983) US Patent 4410501

33. Notari B (1996) Adv Catal 41:253-334

34. Sayari A (1996) Chem Mater 8:1840-1852

35. Pérez-Ramírez J, Kapteijn F, Mul G, Xu XD, Moulijn JA (2002) Catal Today 76:55-74

36. Ricchiardi G, Damin A, Bordiga S, Lamberti C, Spanò G, Rivetti F, Zecchina A (2001) J Am Chem Soc 123:11409-11419

37. Fan WB, Duan RG, Yokoi T, Wu P, Kubota Y, Tatsumi T (2008) J Am Chem Soc 130:10150-10164

38. Li C, Xiong G, Xin Q, Liu JK, Ying PL, Feng ZC, Li J, Yang WB, Wang YZ, Wang GR, Liu XY, Lin M, Wang XQ, Min EZ (1999) Angew Chem Int Ed 38:2220-2222

39. Li C, Xiong G, Liu JK, Ying PL, Xin Q, Feng ZC (2001) J Phys Chem B 105:2993-2997

40. Sun KJ, Fan FT, Xia HA, Feng ZC, Li WX, Li C (2008) J Phys Chem C 112:16036-16041

41. Yu Y, Xiong G, Li C, Xiao FS (2000) J Catal 194:487-490

42. Yu JQ, Feng ZC, Xu L, Li MJ, Xin Q, Liu ZM, Li C (2001) Chem Mater 13:994-998

43. Li Y, Feng ZC, Lian YX, Sun KQ, Zhang L, Jia GQ, Yang QH, Li C (2005) Microporous Mesoporous Mater 84:41-49

44. Yang QH, Wang SL, Lu JQ, Xiong G, Feng ZC, Xin Q, Li C (2000) Appl Catal A Gen 194-195:507-514

45. Cundy CS, Cox PA (2005) Microporous Mesoporous Mater 82:1-78

46. Kirschhock CEA, Kremer SPB, Grobet PJ, Jacobs PA, Martens JA (2002) J Phys Chem B 106:4897-4900

47. Kirschhock CEA, Kremer SPB, Vermant J, Tendeloo GV, Jacobs PA, Martens JA (2005) Chem Eur J 11:4306-4313

48. Burkett SL, Davis ME (1994) J Phys Chem 98:4647-4653

49. Thompson RW (1992) Zeolites 12:837-840

50. Gonthier S, Gora L, Güray I, Thompson RW (1993) Zeolites 13:414-418

51. Valtchev VP, Bozhilov KN (2005) J Am Chem Soc 127:16171-16177

52. Nikolakis V, Vlacho DG, Tsapatsis M (1998) Microporous Mesoporous Mater 21:337-346

53. Weckhuysen BM, Baetens D, Schoonheydt RA (2000) Angew Chem Int Ed 39:3419-3422

54. Dutta PK, Shieh DC, Puri M (1987) J Phys Chem 91:2332-2336

55. Dutta PK, Puri M (1987) J Phys Chem 91:4329-4333

56. Grandjean D, Beale AM, Petukhov AV, Weckhuysen BM (2005) J Am Chem Soc 127:14454-14465 
57. O'Brien MG, Beale AM, Catlow CRA, Weckhuysen BM (2006) J Am Chem Soc 128:11744-11745

58. Fan FT, Feng ZC, Li GN, Sun KJ, Ying PL, Li C (2008) Chem Eur J 14:5125-5129

59. Fan FT, Feng ZC, Sun KJ, Guo ML, Guo Q, Song Y, Li WX, Li C (2009) Angew Chem Int Ed 48:8743-8747

60. Fan FT, Feng ZC, Li C (2010) Chem Soc Rev 39:4794-4801

61. Fan FT, Li C (2013) Sci Sin Chim 43:1818-1830

62. Fan FT, Sun KJ, Feng ZC, Xia HA, Han B, Lian YX, Ying PL, Li C (2009) Chem Eur J 15:3268-3276

63. Lewis DW, Catlow CRA, Sankar G, Carr SW (1995) J Phys Chem 99:2377-2383

64. Fejes P, Nagy JB, Halász J, Oszkó A (1998) Appl Catal A Gen 175:89-104

65. Twu J, Dutta PK, Kresge CT (1991) Zeolites 11:672-679

66. Xiong G, Yu Y, Feng ZC, Xin Q, Xiao FS, Li C (2001) Microporous Mesoporous Mater 42:317-323

67. Mcmillan P (1984) Am Mineral 69:622-644

68. Zhang FZ, Guo XW, Wang XS, Li G, Zhou JC, Yu JQ, Li C (2001) Catal Lett 72:235-239

69. Damin A, Bordiga S, Zecchina A, Lamberti C (2002) J Chem Phys 117:226-237

70. Zhuang JQ, Yang G, Ma D, Lan XJ, Liu XM, Han XW, Bao XH, Mueller U (2004) Angew Chem Int Ed 43:6377-6381

71. Wells DH, Delgass WN, Thomson KT (2004) J Am Chem Soc 126:2956-2962

72. Spanò E, Tabacchi G, Gamba A, Fois E (2006) J Phys Chem B 110:21651-21661

73. Bordiga S, Bonino F, Damin A, Lamberti C (2007) Phys Chem Chem Phys 9:4854-4878

74. Guo Q, Sun KJ, Feng ZC, Li GN, Guo ML, Fan FT, Li C (2012) Chem Eur J 18:13854-13860

75. Bordiga S, Damin A, Bonino F, Ricchiardi G, Lamberti C, Zecchina A (2002) Angew Chem Int Ed 41:4734-4737

76. Guo Q, Feng ZC, Li GN, Fan FT, Li C (2013) J Phys Chem C 117:2844-2848

77. Pérez-Ramírez J, Gallardo-Llamas A (2005) J Phys Chem B 109:20529-20538

78. Sun Q, Gao ZX, Chen HY, Sachtler WMH (2001) J Catal 201:89-99

79. Zhu Q, Teeffelen RMV, van Santen RA, Hensen EJM (2004) J Catal 221:575-583

80. Panov GI, Uriarte AK, Rodkin MA, Sobolev VI (1998) Catal Today 41:365-385

81. Heyden A, Peters B, Bell AT, Keil FJ (2005) J Phys Chem B 109:1857-1873

82. Zecchina A, Rivallan M, Berlier G, Lamberti C, Ricchiardi G (2007) Phys Chem Chem Phys 9:3483-3499

83. El-Malki EM, van Santen RA, Sachtler WMH (2000) J Catal 196:212-223

84. Sun KQ, Xia HA, Feng ZC, van Santen R, Hensen E, Li C (2008) J Catal 254:383-396

85. Hensen EJM, Zhu Q, van Santen RA (2005) J Catal 233:136-146

86. Sun KQ, Xia HA, Hensen E, van Santen RA, Li C (2006) J Catal 238:186-195

87. Heyden A, Hansen N, Bell AT, Keil FJ (2006) J Phys Chem B 110:17096-17114

88. Hansen N, Heyden A, Bell AT, Keill FJ (2007) J Phys Chem C 111:2092-2101

89. Kondratenko EV, Perez-Ramirez J (2007) Catal Today 121:197-203

90. Dubkov KA, Ovanesyan NS, Shteinman AA, Starokon EV, Panov GI (2002) J Catal 207:341-352

91. Berrier E, Ovsitser O, Kondratenko EV, Schwidder M, Grünert W, Brückner A (2007) J Catal 249:67-78
92. Xia HA, Sun KQ, Sun KJ, Feng ZC, Li WX, Li C (2008) J Phys Chem C 112:9001-9005

93. Brunold TC, Tamura N, Kitajima N, Moro-oka Y, Solomon EI (1998) J Am Chem Soc 120:5674-5690

94. Yang G, Zhou LJ, Liu XC, Han XW, Bao XH (2007) Catal Commun 8:1981-1984

95. Carrano CJ, Carrano MW, Sharma K, Backes G, Sanders-Loehr J (1990) Inorg Chem 29:1865-1870

96. Jensen MP, Lange SJ, Mehn MP, Que EL, Que L (2003) J Am Chem Soc 125:2113-2128

97. Xia HA, Sun KQ, Fan FT, Sun KJ, Su WG, Feng ZC, Ying PL, Li C (2008) J Catal 259:269-275

98. Xia HA, Fleischman SD, Li C, Scott SL (2011) J Phys Chem Lett 2:190-195

99. Wang JY, Xia HA, Ju XH, Feng ZC, Fan FT, Li C (2013) J Catal 300:251-259

100. Xia HA, Sun KQ, Liu ZM, Feng ZC, Ying PL, Li C (2010) J Catal 270:103-109

101. Xia HA, Sun KQ, Feng ZC, Li C (2011) J Phys Chem C 115:542-548

102. Wang JY, Li GN, Ju XH, Xia HA, Fan FT, Wang JH, Feng ZC, Li C (2013) J Catal 301:77-82

103. Jung KT, Bell AT (2000) J Mol Catal A 163:27-42

104. Zhang J, Xu Q, Feng ZC, Li MJ, Li C (2008) Angew Chem Int Ed 47:1766-1769

105. Sakata Y, Nakagawa T, Nagamatsu Y, Matsuda Y, Yasunaga R, Nakao E, Imamura H (2014) J Catal 310:45-50

106. Li C, Li MJ (2002) J Raman Spectrosc 33:301-308

107. Li MJ, Feng ZC, Ying PL, Xin Q, Li C (2003) Phys Chem Chem Phys 5:5326-5332

108. Zhang J, Li MJ, Feng ZC, Chen J, Li C (2006) J Phys Chem B 110:927-935

109. Zhang J, Xu Q, Li MJ, Feng ZC, Li C (2009) J Phys Chem C 113:1698-1704

110. Xu Q, Zhang J, Feng ZC, Ma Y, Wang X, Li C (2010) Chem Asian J 5:2158-2161

111. Wang X, Xu Q, Fan FT, Wang XL, Li MR, Feng ZC, Li C (2013) Chem Asian J 8:2189-2195

112. Wang X, Xu Q, Li MR, Shen S, Wang XL, Wang YC, Feng ZC, Shi JY, Han HX, Li C (2012) Angew Chem Int Ed 51:13089-13092

113. Shen S, Wang XL, Chen T, Feng ZC, Li C (2014) J Phys Chem C 118:12661-12668

114. Playford HY, Hannon AC, Barney ER, Walton RI (2013) Chem Eur J 19:2803-2813

115. Yanagida T, Sakata Y, Imamura H (2004) Chem Lett 33:726-727

116. Wang X, Shen S, Jin SQ, Yang JX, Li MR, Wang XL, Han HX, Li C (2013) Phys Chem Chem Phys 15:19380-19386

117. Kim HS, Stair PC (2009) J Phys Chem A 113:4346-4355

118. Jin SQ, Guo ML, Fan FT, Yang JX, Zhang Y, Huang BK, Feng ZC, Li C (2013) J Raman Spectrosc 44:266-269

119. Jin SQ, Fan FT, Guo ML, Zhang Y, Feng ZC, Li C (2014) Rev Sci Instrum 85:046105-(1-3)

120. Grunwaldt JD, Wagner JB, Dunin-Borkowski RE (2013) ChemCatChem 5:62-80

121. Weckhuysen BM (2009) Angew Chem Int Ed 48:4910-4943

122. Stavitski E, Weckhuysen BM (2010) Chem Soc Rev 39:4615-4625

123. Guo ML, Feng ZC, Li GN, Hofmann JP, Pidko EA, Magusin PCMM, Guo Q, Weckhuysen BM, Hensen EJM, Fan FT, Li C (2012) Chem Eur J 18:12078-12084

124. Guo ML, Feng ZC, Hofmann JP, Weckhuysen BM, Fan FT, Li C (2013) Chem Eur J 19:14200-14204

125. Park KD, Kim YH, Park JH, Park JS, Lee HS, Yim SY, Lee YH, Jeong MS (2012) J Raman Spectrosc 43:1931-1934 
126. Nijhuis TA, Tinnemans SJ, Visser T, Weckhuysen BM (2003) Phys Chem Chem Phys 5:4361-4365

127. Brandhorst M, Cristol S, Capron M, Dujardin C, Vezin H, Le bourdon G, Payen E (2006) Catal Today 113:34-39

128. Guerrero-Pérez MO, Bañares MA (2006) Catal Today $113: 48-57$
129. Zhao CL, Wachs IE (2008) J Phys Chem C 112:11363-11372

130. Patlolla A, Carino EV, Ehrlich SN, Stavitski E, Frenkel AI (2012) ACS Catal 2:2216-2223

131. Xu J, Deng YQ, Luo Y, Mao W, Yang XJ, Han YF (2013) J Catal 300:225-235 